\title{
Tests of the generality of the principle of encoding specificity
}

\author{
LEO POSTMAN \\ University of California, Berkeley, California 94720
}

\begin{abstract}
Two empirical tests of the principle of encoding specificity are reported. In Experiment $I$, the normative strength of the cues presented on the input and on the recall trial was varied factorially. To lessen the emphasis on strictly associative learning, only half the items were cued in each phase of the study-recall cycle. Recall was higher when the cues remained the same than when they changed. However, regardless of the condition of input cuing, strong output cues were substantially more effective than weak ones. In Experiment II, the to-be-remembered words were shown in the presence of weak cues on the input trial. Recognition in the context of strong extralist cues was compared with recall to the original input cues. On the test of cued recognition, the target words were either generated by the subjects as free associates or presented to them as items on a test constructed by the experimenter. Contrary to previous findings, recall was not found to be superior to recognition. The phenomena of cue-dependent forgetting that have been interpreted as evidence for the principle of encoding specificity appear to have limited generality.
\end{abstract}

This study is concerned with the empirical validity of the principle of encoding specificity. The principle asserts that a retrieval cue, and in particular an extralist cue. can be effective only if the to-be-remembered (TBR) item has been specifically encoded with respect to that cue during input (Thomson \& Tulving, 1970; Tulving \& Thomson. 1973). That is, the stored information must include the relation between the TBR word and the extralist cue if the latter is to provide access to the former. The existence of the requisite relation in semantic memory does not ensure that such will be the case. since the TBR item has to be retrieved from the episodic store (Tulving, 1972); which semantic relations are represented in the episodic trace depends on the conditions of encoding. This position is to be contrasted with generation-recognition models (Anderson \& Bower. 1972; Bahrick, 1970; Kintsch, 1970) which assume that (a) preexisting semantic relations determine the probability with which a particular target item is generated in the presence of a cue, and (b) decisions about the correctness of generated items are made on the basis of occurrence information associated with the representations of the targets. If it is further assumed that each word has a unique representation in memory, the effectiveness of an extralist cue should be determined primarily by the strength of its preexisting relation to the target and should be largely independent of the semantic context at the time of input.

The basic issue between these two positions hinges on the conditions believed to determine the

This research was supported by Grant MH-12006 from the National Institute of Mental Health. The assistance of Sheila Burns and Deborah Bekerian is gratefully acknowledged. recognition of generated targets. It is known that the power of extralist cues to elicit potential responses is not influenced by the prior presentation of the TBR words in different contexts (Tulving \& Thomson, 1973). If an extralist cue does not produce the expected enhancement of recall, the locus of the failure must. therefore. be in the recognition phase. It has been suggested that such an outcome can be accommodated by a generation-recognition model on the assumption that recognition is based on the senses. rather than the orthographic and phonemic properties, of words. That is, word senses rather than words are generated and have to be recognized before a target word is recalled (Reder, Anderson, \& Bjork, 1974: for a related argument, see Nelson, Wheeler, Borden, \& Brooks. 1974).

The proposed modified version of the generationrecognition model and the principle of encoding specificity share the supposition that changes in context are likely to produce drastic variations in the encoded representations of nominally identical verbal units. Granted that context influences encoding, the question arises of how probable it is that successive encodings of the same word will be sufficiently different to preclude recognition of generated targets. If we conceive of words as aggregates of features, it is reasonable to expect a substantial amount of overlap among the features that are perceived and stored during successive exposures to the same word. What is likely to change from one occasion to the next is the selective emphasis given to specific features and the pattern of associative pathways linking the target to other words. The vast majority of words are not homographs with alternative and unrelated meanings. A priori. it would appear more plausible to apply to 
context-dependent variations in encoding Woodworth's (1938) classical concept of "schema with correction," where schema would refer to a relatively invariant core of semantic features, and correction to the coding operations that are tied to a specific context.

The available experimental evidence bearing on the principle of encoding specificity is inconclusive. Current investigations center on two important findings (Thomson \& Tulving, 1970; Tulving \& Thomson, 1973) which appeared to give strong support to the principle. One of these concerns the limitations on the effectiveness of extralist cues in aiding recall. When TBR items were presented in the context of weak normative associates, recall cued by these associates was considerably higher than uncued recall. However, recall cued by strong normative associates was no better, and under some circumstances considerably worse, then uncued recall. The latter effect was observed after a series of set-inducing lists designed to build up the expectation that the cues would remain constant and thus to encourage their use in the encoding of the TBR words. The second major finding was the high rate of recognition failure for TBR words which subjects were able to generate as free associates in the presence of strong extralist cues. The fact that recognition was substantially lower than recall to the original weak cues is clearly emharrassing to a generationrecognition model and was viewed as strong evidence for encoding specificity. In these comparisons of recognition and recall, set-inducing lists were again used and the different tets were administered to the same subjects in succession.

Subsequent investigations have shown that these apparent manifestations of encoding specificity-the lack of facilitation by strong extralist cues in recall and the superiority of recall over recognition under the experimental arrangements mentioned aboveare likely to be found only under narrowly circumscribed conditions: (a) In a more recent experiment, Tulving (1974) obtained these effects only when the level of performance was depressed by interference from a preceding test of retention. (b) The shift from weak to strong cues produced much larger decrements when the frequency of usage of the TBR words was high rather than low, presumably because variability of encoding is directly related to frequency (Reder, Anderson, \& Bjork, 1974). (c) When Santa and Lamwers (1974) informed subjects about the associative relationship between strong extralist cues and TBR words, recall was greatly enahoned and far superior to uncued recall. In that study, recognition on a multiple-choice test, with high associates of the strong cues as distractors, was better than uncued recall or recall to the strong cues.

It remains uncertain whether and to what extent the semantic similarity between input cues and extralist cues intluences performance. Tulving (1974) found that the degree of semantic congruity between successive cues had only a slight and nonsignificant influence on recall and recognition. Murphy and Wallace (1974) did observe higher recall to semantically similar than to semantically dissimilar cues, but the difference was small relative to that attributable to the switch from old to new cues. This finding brings into focus the possibility that the sheer novelty of the extralist cues, as distinct from the concomitant changes in semantic interpretation, is a critical factor in producing the phenomena ascribed to encoding specificity.

The task demands in the relevant experiments are essentially those of paired-associate learning, especially after the presentation of set-inducing lists. When the TBR word, B, is presented in the context of a weak cue. A, their spatio-temporal contiguity is likely to become a salient feature of the trace of the input. and the more so as the experimental arrangements deliberately direct the subject's attention to cue-response contigencies. A strong extralist cue may then be relatively ineffective because it is new, and not just because it imposes a changed semantic interpretation on the TBR word. It is a fact, of course. that in conventional paired-associate learning failure to recognize a stimulus often leads to failure of recall (Bernbach, 1967; Martin, 1967). Performance in the presence of extralist cues may. furthermore, suffer to the extent that the subject makes use of backward associations to check on the correctness of potential responses (cf. Twedt \& Underwood. 1959; Wolford, 1971). Clearly, cue recognition is not a necessary condition of recall; otherwise, recall in the presence of extralist cues would always be zero. The suggestion is, rather, that in the context of an associative task the presentation of new cues may serve to reduce the number of recall attempts and to increase the probability of false rejections.

The central theoretical question in these experiments is whether variations in verbal context change the semantic interpretation of TBR words to the point where recognition of otherwise available items fails. If the source of the apparent encoding speciticity lies primarily in the constraints imposed by pairwise contingencies, the theoretical implications would be quite different. In particular, the results would then not constitute a strong argument against the "transsituational identity of words" (Tulving \& Thomson, 1973). For this reason, it would appear advisable to minimize rather than to accentuate the strictly associative task demands. In the interest of doing so, the set-inducing tasks can be omitted without risk. If the original weak cues significantly aid recall when they are repeated in the output phase, it can be safely inferred that the subjects paid due attention to these cues. An additional procedure 
designed to reduce the emphasis on pairwise contingencies will be described below.

In the studies under consideration, set-inducing lists are only one of several potential sources of intraexperimental transfer. The interpretation of the critical differences between recognition and recall is necessarily complicated by the administration of successive tests to the same subjects. Other possible sources of bias are inherent in some of the testing procedures used, e.g., the generation of large numbers of semantically related distractors along with the TBR words during a free-association procedure. Systematic manipulation of the conditions of testing should permit an assessment of the magnitude and importance of such biases.

These methodological considerations were taken into account in the present investigation of cue-dependent forgetting. Thus, the purpose of the experiments was to examine the robustness and generality of the phenomena that have been interpreted as evidence for a strong principle of encoding specificity. The theoretical question that requires continuing exploration concerns the degree of stability in the encoding of nominally identical words encountered in varying contexts.

\section{EXPERIMENT I}

The purpose of the first experiment was to test the principle of encoding specificity in cued recall under conditions designed to minimize the emphasis on associative learning. To the extent that the manipulations were successful, input cues provided a semantic context for TBR words and were not treated by the subjects strictly as stimuli for paired associates.

\section{Method}

Design and materials. The learning materials were two lists of 24 words used previously by Tulving and Thomson (1973). The cues used on input and output trials were taken from the same source. For each TBR word, there was a strong and a weak cue which elicited the target with mean normative probabilities of $52 \%$ and $1 \%$, respectively. The strengths of the input cues and of the output cues were varied factorially, so that there were four independent groups that will be designated as strong-strong (S-S), weak-weak (W.W), weak-strong (W-S), and strong-weak (S-W). Under each of these conditions, there were four combinations of cuing operations during input and output, yielding the following subsets within each list: cued-cued (C-C), cued-noncued (C-N), noncued-cued (N-C), and noncued-noncued (N-N). That is, during the input trial, 12 TBR words were accompanied by cues, and the other 12 items were presented by themselves. During the output trial, half of the items cued during input were again cued, whereas for the other half the cues were omitted. Similarly, of the items not cued during input, half were cued during the output trial and the other half were not. The omission of cues for half the TBR words in each phase of the study-recall cycle was expected to weaken if not eliminate the set to structure the task as paired-associate learning. Thus, the total design was a 2 by 2 by 2 by 2 factorial, with strength of successive cues manipulated between groups and treatment of subsets of items manipulated within subjects.

The two lists of words were used equally often. For purposes of the within-group treatments, each list of 24 words was subdivided
Table 1

Mean Lenient Recall Scores (Experiment I)

\begin{tabular}{llllll}
\hline & \multicolumn{4}{c}{ Subset } & \\
\cline { 2 - 5 } $\begin{array}{c}\text { Condi- } \\
\text { tion }\end{array}$ & C-C & C-N & N-C & N-N & Total \\
\hline S-S & 5.25 & 1.58 & 4.88 & 1.96 & 13.67 \\
W-S & 4.54 & 2.25 & 4.67 & 2.71 & 14.17 \\
W-W & 4.00 & 2.33 & 2.83 & 2.42 & 11.58 \\
S-W & 3.04 & 2.75 & 3.08 & 3.38 & 12.25 \\
\hline
\end{tabular}

Note-MS $=2.34$ and 1.24 for between-subjects and withinsubjects comparisons, respectively.

into four groups of six items each. The four groups of items were rotated through the cuing treatments, so that all comparisons between and within conditions are based on the same words.

Procedure. The list was presented once on a memory drum at a 3-sec rate. The TBR words were shown in capital letters. The cue words were printed in lowercase letters, were enclosed in parentheses, and appeared to the left of the TBR words. The instructions made it clear that the cue words were meant to serve as hints or aids in learning the capitalized words but were not to be recalled. Three different orders of in put were used equally often for each version of a list. Instructions for a written test of recall were given immediately after the end of list presentation. The subjects in Conditions S-S and W.W were informed that some of the test cues had been shown before and that some would be new; those in Conditions W-S and S-W were told that the cues would be different from the ones presented earlier. There were 24 spaces on the recall sheet, with appropriate cues next to 12 of them. Each set of cues was presented in three different orders and spatial arrangements. The subjects were reminded that the capitalized words were to be recalled and were asked to write down any additional words at the bottom of the page. Three minutes were allowed for the test of recall.

Subjects. There were 24 subjects in each of the four groups. The subjects were undergraduate students at the University of California who were not necessarily naive to verbal learning experiments. A randomized block procedure was used to assign subjects to conditions.

\section{Results}

Lenient scores. Table 1 shows the mean lenient scores for the four subsets of items in each condition. These measures are based on the total numbers of words recalled, regardless of whether or not they were given to the appropriate cues (in Subsets C-C and $\mathrm{N}-\mathrm{C})$. We consider cued recall first. The pattern of scores for the $\mathrm{C}-\mathrm{C}$ subset shows that (a) recall was higher when the cues during input and during output remained the same than when they changed, i.e., $(\mathrm{S}-\mathrm{S}+\mathrm{W}-\mathrm{W})>(\mathrm{W}-\mathrm{S}+\mathrm{S}-\mathrm{W})$; and (b) in both these cases, recall was higher when the output cues were strong than when they were weak, i.e., S-S $>$ W-W and $\mathrm{W}-\mathrm{S}>\mathrm{S}-\mathrm{W}$. For the N-C subset, the type of output cue was the only effective variable: performance was substantially better in the presence of strong cues than of weak ones.

The level of noncued recall (C-N and $\mathrm{N}-\mathrm{N})$ tended to be inversely related to that of cued recall; the scores were lowest under Condition S-S and highest under Condition S-W. Apparently, subjects focused on the recall of noncued single items when they found the cues provided to them ineffective.

To determine the magnitude of the effects produced 
Table 2

Mean Differences Between Cued and Noncued Subsets in Recall (Experiment I)

\begin{tabular}{ccc}
\hline Condition & C-C - C-N & N-C - N-N \\
\hline S-S & 3.67 & 2.92 \\
W-S & 2.29 & 1.96 \\
W-W & 1.67 & .41 \\
S-W & .29 & -.30 \\
\hline
\end{tabular}

Note-MS $=2.76$ and 2.35 for between-subjects and withinsubjects comparisons, respectively.

by the output cues per se, it is necessary to compare the pairs of treatments that differed in the recall phase only. The differences to be considered are those between $\mathrm{C}-\mathrm{C}$ and $\mathrm{C}-\mathrm{N}$, on the one hand, and those between N-C and N-N, on the other. The mean differences are presented in Table 2 and fully confirm the conclusions based on the raw values of cued recall.

The statistical analysis of these results was carried out in three steps. First, the recall scores were subjected to an overall analysis of variance. Strength of output cue was found to interact significantly with subset, $F(3.276)=31.50$. The higher order interaction, Strength of Input Cue by Strength of Output Cue by Subset, was likewise significant, $\mathrm{F}(3.276)=10.53$. The next step was an analysis of noncued recall (C-N and N-N). Strength of output cue was a significant source of variance, as was the Strength of Input Cue by Strength of Output Cue interaction, $F(1,92)=9.72$ and 13.44 , respectively. Finally, the difference scores shown in Table 2 were analyzed. The two sources of variance mentioned in the preceding analysis were again significant, $F(1,92)$ $=83.22$ and 21.20 . As already noted, the trends for noncued and for cued recall were complementary, and the reliability of this pattern was confirmed by the statistical tests. All the effects mentioned above were significant at the .01 level.

It should be noted that the difference between the C-C and C-N subsets in Condition W-W was clearly significant, $t(23)=5.06, p<.01$. Taken in conjunction with the fact that there was only a small separation between the $\mathrm{N}-\mathrm{C}$ and $\mathrm{N}-\mathrm{N}$ subsets, this difference indicates that the subjects paid attention to the $W$ cues during input and could make use of these same cues if they were presented again at the time of test. It is quite possible, however, that $S$ cues were used more frequently than $\mathrm{W}$ cues during the original encoding of the TBR words. As we will try to show, however, an adequate test of the hypothesis of encoding specificity requires only that $W$ cues be used in the encoding of TBR words to some significant degree, and not necessarily to the same extent as $S$ cues.

Stringent scores. The mean stringent scores for Subsets C-C and N-C are presented in Table 3. For purposes of stringent scoring, credit was given only for responses given to the appropriate cues. The pattern of differences is the same as for lenient scores. Strength of the output cue was a significant source of variance, $F(1,92)=94.68$. All interactions involving that variable were also significant. The values of $F(1.92)$ were 11.78 for Strength of Output Cue by Strength of Input Cue. 11.58 for Strength of Output Cue by Subset, and 17.94 for the higher order interaction. There was also an interaction of strength of input cue with subset, $F(1,92)=8.11$ : the difference between C-C and N-C was substantially larger when the input cue was weak than when it was strong. Again, all the effects were significant at the .01 level.

Errors in recall. The fact that the use of the same cue during presentation and test favored recall can be simply interpreted as reflecting the development of specific associations during the input trial. However, one may also choose to consider this finding as evidence for some degree of encoding specificity. If so, the question arises as to what extent the specificity lay in the encodings of the TBR words rather than in the pairwise contingencies between cues and responses. Some information bearing on this question is provided by an examination of the relative frequencies with which correct responses to strong cues were written down as single words rather than paired with the appropriate stimuli. Under the C-C treatment, the percentage of such responses was 11.1 for Group S-S and 21.1 for Group W-S. The corresponding percentages under the $\mathrm{N}-\mathrm{C}$ treatment were 9.2 and 20.7. Apparently, subjects recognized novel cues as such and were reluctant to pair old responses with them, even when they had decided that those responses were correct. The fact that the difference between the two groups was comparable for the C-C and N-C subsets indicates that classes of cues as well as individual stimuli were categorized as old or new.

The frequencies of extralist intrusions are listed in Table 4. (The pattern remains unchanged when these frequencies are expressed as percentages of total responses.) The intrusions were divided into three categories: importations from outside the list, strong cues, and weak cues. As would be expected, the numbers of importations were inversely related to the overall level of recall and hence were higher in Conditions W-W and S-W than in Conditions S-S and

Table 3

Mean Stringent Scores (Experiment I)

\begin{tabular}{ccc}
\hline & \multicolumn{2}{c}{ Subset } \\
\cline { 2 - 3 } Condition & C-C & N-C \\
\hline S-S & 4.29 & 4.00 \\
W-S & 3.04 & 3.17 \\
W-W & 2.33 & .17 \\
S-W & .29 & .25 \\
\hline
\end{tabular}

Note-MS $=4.16$ and 1.08 for between-subjects and withinsubjects comparisons, respectively. 
W-S. Intrusions of strong cues were relatively rare and showed only slight variations across conditions. The occurrence of weak cues as intrusions was almost entirely dependent on the prior exposure to these particular words during the input trial. It is worth noting that the frequency of such errors was greater in Condition W-W than in Condition W-S. The presence of weak cues on the protocol sheet apparently primed the recall of items of the same class. In general, the distributions of intrusion frequencies bear out the conclusion that the weak input cues were by no means disregarded by the subjects; however, confusions between weak cues and TBR words were not uncommon, particularly in Condition W-W.

\section{Discussion}

The results of this experiment fail to support the principle of encoding specificity. The following predictions are entailed by a strict specificity position: (a) There should be no difference between the C-C and $\mathrm{C}-\mathrm{N}$ subsets in Condition W-S; furthermore, on the assumption that subjects are likely to encode TBR words spontaneously with respect to strong cues, recall should be higher under the $\mathrm{N}-\mathrm{C}$ than under the $\mathrm{C}$-C treatment in that condition. (b) There should be no difference in the magnitude of the cuing effect (C.C minus C-N) between Conditions W-S and S-W since equivalent contextual changes occurred in these two situations. These predictions are clearly disconfirmed by the data.

It should be borne in mind that the predictions were evaluated under a mixed-list procedure, with half the items noncued both during presentation and at the time of test. Since the principle of specificity pertains to the encoding of individual items, it is reasonable to extend the deductions to the present conditions. A mixed-list arrangement, in which the strength of the input cues and of the output cues was varied factorially, was used previously in a test of the principle of encoding specificity (Thomson \& Tulving, 1970. Experiment III). Furthermore, the basic conclusions remain the same whether the measures of cued recall are considered directly or compared with corresponding values for noncued recall.

An attempt might be made to discount the present tindings on the ground that weak input cues were not used consistently in the encoding of TBR words; to the extent that such cues were disregarded, strong extralist cues might remain appropriate and facilitate recall. The substantial cuing effects in Condition W-S, and the difference between the latter and Condition $S-W$, could then be reconciled with the principle of encoding specificity. Internal analysis shows, however, that such an explanation cannot take adequate account of the entire pattern of results. The difterence between the $\mathrm{C}-\mathrm{C}$ and $\mathrm{C}-\mathrm{N}$ subsets in Condition W.W constitutes independent evidence
Table 4

Frequencies of Extralist Intrusions (Experiment I)

\begin{tabular}{cccc}
\hline & \multicolumn{3}{c}{ Type of Intrusion } \\
\cline { 2 - 4 } $\begin{array}{c}\text { Condi- } \\
\text { tion }\end{array}$ & $\begin{array}{c}\text { Impor- } \\
\text { tations }\end{array}$ & $\begin{array}{c}\text { Strong } \\
\text { Cues }\end{array}$ & $\begin{array}{r}\text { Weak } \\
\text { Cues }\end{array}$ \\
\hline S-S & 19 & 11 & 1 \\
W-S & 16 & 6 & 12 \\
W-W & 33 & 8 & 21 \\
S-W & 30 & 9 & 2
\end{tabular}

that the TBR words were encoded with respect to weak input cues at least part of the time. A very conservative estimate based on the gains presented in Table 2 is that such was the case for no fewer than about two items. Now let us add the drastic, and rather implausible. assumption that in the absence of input cues all items were encoded spontaneously with respect to the strong cues to be presented later. It follows that in Condition W-S recall should have been higher under the $\mathrm{N}-\mathrm{C}$ than under the C-C treatment, since at least some items were inappropriately encoded in the latter, but not in the former, case. The fact is that the scores for these two subsets were virtually identical; as can be seen in Table 2, the gain was actually somewhat higher under the C-C than under the $\mathrm{N}-\mathrm{C}$ treatment.

The finding that recall of $\mathrm{N}-\mathrm{C}$ subsets was higher in the presence of strong than of weak extralist cues does not bear critically on the theoretical questions at issue. This result is predicted directly by generation-recognition models; it can be accommodated by the specificity position on the assumption of spontaneous encoding with respect to strong extralist cues. It is the virtual equality of scores for the $\mathrm{C}-\mathrm{C}$ and $\mathrm{N}-\mathrm{C}$ subsets in the presence of strong cues that creates difficulties for a specificity interpretation. That holds true not only for Condition W-S, where a difference in favor of the N-C arrangement had to be predicted, but also for Condition S-S. In the latter case, the smallness of the advantage of the C-C over the $\mathrm{N}-\mathrm{C}$ treatment puts a rather heavy strain on the assumption of spontaneous encoding with respect to strong extralist cues. The total pattern of results, including the superiority of cued recall in Condition W-S over that in Condition S-W, conforms rather well to the expectations derived from a generation-recognition model.

The present results are, of course, at variance with those of several earlier studies, particularly with respect to the relative efficiency of recall in Condition W-S. This reversal may be attributed to the manipulations used here to reduce the salience of strictly pairwise contingencies. It thus becomes reasonable to conclude that the subjects' reaction to the novelty of the cues in what they perceived as an essentially associative task was largely responsible for previously reported failures of strong extralist cues to 
facilitate recall. The effects of instructions concerning the relation between TBR words and cues (Santa \& Lamwers, 1974) are consistent with this interpretation. Such instructions represent, of course, a direct intervention in the subjects' recall strategies. It has now been shown that in the absence of either special recall instructions or set-inducing operations TBR words have a demonstrable degree of transsituational stability.

\section{EXPERIMENT II}

The next experiment is concerned with the phenomenon of recognition failure for words that are available for recall. The basic empirical finding at issue is that words originally processed in the context of weakly associated cues can be recalled better in the presence of these cues than they can be recognized when given as responses to strong normative associates. In view of the methodological problems mentioned earlier, the following questions warrant consideration. (1) Is the recognition failure caused by the change in context attendant upon the shift from weak to strong cues, or is it peculiar to a situation in which discriminations have to be made among free associates? (2) Does the superiority of recall over recognition remain in evidence when intrasession transfer effects are eliminated and appropriate tests are administered to independent groups?

\section{Method}

Design. The design comprised two response-generation conditions and two control conditions. Under the former conditions, the procedure of Tulving and Thomson (1973) was followed with some modifications. After exposure to a list of words accompanied by weakly associated cues, the subjects generated a subset of the TBR items as free associates to strong extralist cues and were then tested in succession for (a) recognition of the generated items and (b) recall of all items to the original cues. In the present experiment, the number of free associates was restricted to two (rather than four or six). Since the majority of generated TBR items are given as primary responses, it was deemed desirable to reduce the amount of interference from semantically similar distractors by limiting the number of associates to two. Furthermore, with a view to manipulating the amount of such interference directly, different instructions were given to the two response-generation groups in the free-association phase of the experiment. In Condition HA (high associates), the subjects were instructed to produce two associates that were both highly related to the cue; in Condition MA (mixed associates), one of the associates was to be highly related, and the other slightly related, to the cue.

The subjects in the recognition control condition were tested for recognition of the TBR words, which were presented either in the presence of strong extralist cues or singly. The recognition test was followed by a test of cued recall, just as in Conditions HA and MA. Under the recall control condition. the subjects were tested for recall of the TBR words in the presence of the original input cues. The interval between the end of list presentation and the first test of retention was the same for all groups.

Materials. The lists, input cues, and extralist cues were the same as in Experiment 1 . The 24 words in a list were again divided into groups of 6 , and all possible subsets of 12 were used equally often when a test was given on half the items. In addition, there were 12 words which were employed as filler cues during the free-association procedure. The filler cues elicit their primary associates with a mean normative probability of .53 , which matches the mean of .52 for the strong extralist cues.

Procedure. The sequence of events under the various conditions can be conveniently outlined by dividing the total experimental session into four phases and indicating the treatment of each group in the successive phases.

Phase 1: The first phase always consisted of the presentation of a list of 24 TBR words accompanied by weakly associated cues. The method and rate of presentation were the same as in Experiment $\mathrm{I}$.

Phase 2: In the second phase, the response-generation groups performed the free-association task. Twenty-four stimuli were listed on the free-association forms-12 strong extralist cues to TBR words and 12 tiller cues. Twelve minutes were allowed for this task. The control groups worked on a series of arithmetic problems during the corresponding period.

Platse 3: In the third phase. the subjects in Conditions HA and MA were given a recognition test on the items they had generated. They were instructed to encircle those items that had occurred in the input list and to cross out all other words. (A few subjects failed either to encircle or to cross out some of the words. All such cases were scored as rejections.) Thus, the subjects had to make decisions about 48 items. namely two associates of each of 24 cues. The two control groups were also tested in this phase. The test administered to the recognition control group again consisted of 48 items: (a) 12 TBR words accompanied by strong extralist cues; (b) 12 distractors accompanied by strong extralist cues; (c) 12 single TBR words; and (d) 12 single distractors. The distractors were words from the list not presented to the subject. For the cued items. the scores of the recognition control group could be compared directly with those of Groups HA and MA. (The contrast between uncued and cued items would provide information about the relative effects on recognition of the deletion of a weak cue and of its replacement by a strong one.) Finally, the test administered to the recall control group consisted of the presentation of the original input cues, with instructions to write down the TBR words next to the appropriate cues, or separately. just as in Experiment I. Three minutes were allowed for the tests in this phase.

Phase 4: In the fourth phase, a test of cued recall like the one described just above was given to the three groups that had previously been tested for recognition.

Subjects. There were 24 subjects in each of the four groups, drawn from the same population, and assigned to conditions in the same nauner, as in Experiment 1.

Scoring. Several scoring conventions that were adopted in the analysis of this experiment should be indicated at the outset. (1) Of the free associates produced by the generation-response groups. only those target items given to the appropriate extralist cues were considered. Targets were given to inappropriate cues only occasionally. (2) Only the data of subjects who gave no fewer than three target items as free associates were included in the analyses. This criterion resulted in the elimination of two subjects each in Conditions HA and MA. Measures of cued recall for these subjects indicate that the application of this rule entailed no systematic selection for ability. (3) Both stringent and lenient recall scores were calculated. Primary attention should be directed toward the former since the principle of encoding specificity assumes encoding of 'TBR words with respect to the particular cues presented at input. (4) In all comparisons between the response-generation groups and the recognition control group, subjects tested with the same subset of extralist cues were yoked. The particular subjects to be yoked were chosen on the basis of the order of assignment to blocks. For purposes of comparison, only the TBR words produced by the response-generation subject were then scored in the protocol of the control subject. (5) A yoking procedure based on list assignment was used in comparisons between the response-generation groups and the recall control group. Again, only generated TBR words were scored in the control protocols. (6) Both recognition and recall scores were expressed throughout as proportions of relevant items. 


\section{Results}

Control groups. The measures of performance for the two control groups are presented in Table 5 . We note first of all that for the recognition control group there were only minor and nonsignificant differences between the cued and the noncued subsets. Deletion and change of context had. therefore. equivalent effects on recognition and did not influence subsequent cued recall differentially. The second major finding is that recognition hit rates were higher than both stringent and lenient scores of the recall control group. For purposes of an overall analysis. the measures of cued and of noncued recognition were treated as independent. but degrees of freedom for error were based on the number of subjects. Orthogonal comparisons show that the combined measures of recognition surpass both stringent and lenient recall. $F(1.46)=11.30(p<.01)$ and 7.18 $(p<.02)$. respectively. Subsequent pairwise contrasts between the recall and the recognition measures vielded $t$ values ranging from 2.17 to 3.04 . Thus. all the relevant differences are significant at least at the .05 level. If false alarms are subtracted from hit rates. the scores of the two control groups become essentially equal. The validity of such a correction is uncertain at best. In any event. recall in the presence of the original cues was not superior to recognition in a new context. or with context deleted. Finally. it is of interest that the stringent recall scores of the recognition control group were lower than those of the recall control group. These scores are not strictly comparable since the retention interval was shorter under the latter condition. There is a suggestion here. nevertheless, that the presentation of the TBR words along with new cues. or in the absence of the old ones. produced some specitic associative loss. This conclusion is supported by the fact that the differences were only minor for lenient scores.

Response-generation groups. The mean numbers of target words generated during the free-association procedure were $7.3(61.1 \%)$ under Condition HA. and $6.8(56.9 \%)$ under Condition MA. Of these. $87.5 \%$ and $86.6 \sigma_{0}$. respectively, were given as first associates. Thus. the obtained percentages of primary responses-53.5 and 49.3-are quite close to the normative value of 52 . The values for the filler cues were comparable.
Table 5

\begin{tabular}{|c|c|c|c|c|c|}
\hline \multicolumn{6}{|c|}{$\begin{array}{c}\text { Means and Standard Deviations of Performance Measures } \\
\text { Under Control Conditions (Experiment II) }\end{array}$} \\
\hline \multirow[b]{2}{*}{ Condition } & & \multirow[b]{2}{*}{ Hits } & \multirow[b]{2}{*}{ FAs } & \multicolumn{2}{|c|}{ Cued Recall } \\
\hline & & & & $\begin{array}{l}\text { Strin- } \\
\text { gent }\end{array}$ & $\begin{array}{l}\text { Leni- } \\
\text { ent }\end{array}$ \\
\hline \multicolumn{6}{|c|}{ ecognition Control } \\
\hline Cued & $\begin{array}{l}\text { M } \\
\text { SD }\end{array}$ & $\begin{array}{l}.573 \\
.212\end{array}$ & $\begin{array}{l}.135 \\
.151\end{array}$ & $\begin{array}{l}.368 \\
.250\end{array}$ & $\begin{array}{l}.448 \\
.207\end{array}$ \\
\hline Noncued & $\begin{array}{l}\mathrm{M} \\
\mathrm{SD}\end{array}$ & $\begin{array}{l}.590 \\
.145\end{array}$ & $\begin{array}{l}.114 \\
.104\end{array}$ & $\begin{array}{l}.323 \\
.231\end{array}$ & $\begin{array}{l}.420 \\
.199\end{array}$ \\
\hline $\begin{array}{l}\text { ecall } \\
\text { ontrol }\end{array}$ & $\begin{array}{l}\mathrm{M} \\
\mathrm{SD}\end{array}$ & & & $\begin{array}{l}.420 \\
.212\end{array}$ & $\begin{array}{l}.460 \\
.184\end{array}$ \\
\hline
\end{tabular}

Since a high proportion of the target words occurred as first associates. there was only a slight difference in the number of TBR words generated by Groups HA and MA. The question to be considered next is whether the instructions regarding the relation between the cue and the second associate were effective. If they were, there should be a higher degree of commonality among the second associates in Condition HA than in Condition MA. The type-token ratio was, therefore, determined for the second associates given to each of the extralist cues. The mean ratios were .850 and .934 for Groups $H A$ and MA. respectively. The difference was not large but quite consistent across words and is significant at the .01 level by sign test. For the filler cues. the corresponding ratios were .656 and .791 and again differ at the .01 level. It appears that instructions did have a systematic influence on the nature of the second associates.

The measures of recognition of generated responses are shown in Table 6. The hit rates under the two conditions of response generation were similar and considerably higher than in the experiments of Tulving and Thomson (1973). These values can be compared directly with the scores of the yoked control subjects tested after the same retention interval. The proportions of hits were greater under the recognition control than under the response-generation conditions: the same was true for false alarms. The sum of misses and false alarms. which correlates highly with d' (ct. Lnderwood, 1974). was used to evaluate the differences in recognition performance. Neither of the

Table 6

Mean Recognition Scores and Standard Deviations of Response-Generation Groups and Performance Measures of Yoked Control Subjects (Experiment II)

\begin{tabular}{|c|c|c|c|c|c|c|c|}
\hline \multirow[b]{2}{*}{ Condition } & & \multicolumn{2}{|c|}{ Generated Items } & \multicolumn{2}{|c|}{$\begin{array}{c}\text { Yoked Recognition } \\
\text { Control } \\
\end{array}$} & \multicolumn{2}{|c|}{$\begin{array}{c}\text { Yoked Recall } \\
\text { Control }\end{array}$} \\
\hline & & Hits & FAs & Hits & FAs & Stringent & Lenient \\
\hline $\mathrm{HA}$ & $\begin{array}{l}\text { II } \\
\text { SD }\end{array}$ & $\begin{array}{l}.498 \\
.272\end{array}$ & $\begin{array}{l}.060 \\
.074\end{array}$ & $\begin{array}{l}.604 \\
.227\end{array}$ & $\begin{array}{l}.117 \\
.145\end{array}$ & $\begin{array}{l}.385 \\
.241\end{array}$ & $\begin{array}{l}.437 \\
.194\end{array}$ \\
\hline IIA & $\begin{array}{l}\text { II } \\
\text { SD }\end{array}$ & $\begin{array}{l}.462 \\
.266\end{array}$ & $\begin{array}{l}.076 \\
.100\end{array}$ & $\begin{array}{l}.580 \\
.218\end{array}$ & $\begin{array}{l}.129 \\
.152 \\
\end{array}$ & $\begin{array}{l}.440 \\
.329 \\
\end{array}$ & $\begin{array}{l}.465 \\
.304 \\
\end{array}$ \\
\hline
\end{tabular}


Table 7

Mean Proportions of Different Test Outcomes (Experiment 11)

\begin{tabular}{|c|c|c|c|c|c|c|c|c|}
\hline \multirow[b]{2}{*}{ Condition } & \multicolumn{4}{|c|}{ Stringent } & \multicolumn{4}{|c|}{ Lenient } \\
\hline & $\mathrm{RgR}$ & $\operatorname{Rg} \overline{\mathbf{R}}$ & $\overline{\mathrm{Rg}} \mathrm{R}$ & $\overline{\mathrm{RgR}}$ & $\mathrm{RgR}$ & $\mathbf{R g} \overline{\mathbf{R}}$ & $\overline{\mathrm{Rg} R}$ & $\overline{\mathrm{Rg}} \overline{\mathrm{R}}$ \\
\hline HA & .203 & .295 & .178 & .324 & .303 & .195 & .197 & .305 \\
\hline MA & .140 & .319 & .100 & .442 & .195 & .264 & .130 & .412 \\
\hline \multicolumn{9}{|c|}{ Recognition Control } \\
\hline Cued & .254 & .319 & .115 & .313 & .323 & .250 & .125 & .302 \\
\hline Noncued & .239 & .351 & .083 & .327 & .326 & .264 & .094 & .316 \\
\hline
\end{tabular}

Note $-R g=$ recognized, $\overrightarrow{R g}=$ not recognized, $R=$ recalled, $\bar{R}=$ not recalled .

response-generation groups was found to differ reliably from the control group. The interaction of the type of measure (misses vs. false alarms) with treatnent (response-generation vs. control) was, however. signiticant at the .05 level for Condition MA and approached signiticance for Condition HA. $F(1.21)=5.27$ and 3.58, respectively. That is, false alarms accounted for a relatively lower proportion of the errors of response-generation than of control subjects. The implication is that the former adopted a more stringent criterion than did the latter.

No signiticant differences were found when the hit rates of the response-generation groups were compared with the recall scores of yoked recall control subjects. Recognition scores were somewhat higher for Group HA; in the case of Group MA, the levels of performance were quite similar. It will be remembered that recognition was significantly better than recall when the two control groups were compared. The hit rates of the response-generation subjects were sufficiently lower than those of the controls to make this difference no longer significant. There is still no evidence, however, for an advantage of cued recall over recognition.

Within-group comparisons of recognition and recall. We have restricted the statistical evaluation of the differences between recognition and recall to comparisons between independent groups tested after the same interval without any prior exposure to retention tests. In addition. it is useful to examine the "fate" of individual items when tests of recognition and of recall were administered in succession. The values of interest are the proportions of items recognized and not recalled $(\operatorname{Rg} \bar{R})$ and of items not recognized but recalled ( $\overline{\mathrm{Rg}} \mathrm{R})$. The relevant values are shown in Table 7 . When stringent recall scores are considered, $\operatorname{Rg} \bar{R}>\overline{\operatorname{Rg}} \mathrm{R}$ in all cases. For lenient recall scores, the differences are smaller but in the same direction, with the exception of Condition HA, where the two values are virtually identical. As Table 6 shows, the hit rates were somewhat higher under Condition HA than under Condition MA; the divergence in the pattern of successive test outcomes reflects the higher level of cued recall under the former condition.

The within-subject comparisons of recognition and recall have to be viewed with considerable caution, not only because the retention intervals were different, but also because the successive tests were not independent of each other.

Effects of generation-recognition activities on recall. Table 8 show's the proportions of previously tested and untested itenis recalled by the subjects in Conditions HA and MA. The tested items were generated during the free-association procedure; the untested items came from the half of the list for which no extralist cues were presented during the generation phase. Examination of the protocols of the yoked recall control subjects showed that the probabilities of recall for the two sets of items were comparable in the absence of an intervening task. Thus, there was no apparent problem of item selection. (Items which had been cued but not generated were excluded from this analysis because of the presence of subjects from whom the frequency of such cases was either zero or very low.) The scores for the two subsets of items of the recognition control group are also presented in the table for purposes of comparison.

We consider the stringent scores of the response-generation groups first. The overall level of performance was higher under Condition HA than under Condition MA, $F(1,42)=4.96, p<.05$. Tested items were recalled better than untested ones, although not signiticantly so. The increases from stringent to lenient measures favored Condition HA and the tested items. In the analysis of the lenient scores, the difference between conditions is significant

Table 8

Mean Proportions (and Standard Deviations) of Previously Tested and Untested Items Recalled (Experiment II)

\begin{tabular}{|c|c|c|c|c|c|}
\hline \multirow[b]{2}{*}{ Condition } & & \multicolumn{2}{|c|}{ Tested Items } & \multicolumn{2}{|c|}{ Untested Items } \\
\hline & & $\begin{array}{l}\text { Strin- } \\
\text { gent }\end{array}$ & $\begin{array}{c}\text { Leni- } \\
\text { ent }\end{array}$ & $\begin{array}{l}\text { Strin- } \\
\text { gent }\end{array}$ & $\begin{array}{c}\text { Leni- } \\
\text { ent }\end{array}$ \\
\hline HA & $\begin{array}{l}\mathbf{M} \\
\mathrm{SD}\end{array}$ & $\begin{array}{l}.380 \\
.283\end{array}$ & $\begin{array}{l}.500 \\
.261\end{array}$ & $\begin{array}{l}.346 \\
.246\end{array}$ & $\begin{array}{l}.395 \\
.228\end{array}$ \\
\hline MA & $\begin{array}{l}\mathrm{M} \\
\mathrm{SD}\end{array}$ & $\begin{array}{l}.239 \\
.260\end{array}$ & $\begin{array}{l}.325 \\
.234\end{array}$ & $\begin{array}{l}.187 \\
.194\end{array}$ & $\begin{array}{l}.244 \\
.172\end{array}$ \\
\hline \multicolumn{6}{|c|}{ Recognition Control } \\
\hline Cued & $\begin{array}{l}\mathbf{M} \\
\text { SD }\end{array}$ & $\begin{array}{l}.368 \\
.250\end{array}$ & $\begin{array}{l}.448 \\
.207\end{array}$ & & \\
\hline Noncued & $\begin{array}{l}\text { M } \\
\text { SD }\end{array}$ & $\begin{array}{l}.323 \\
.231\end{array}$ & $\begin{array}{l}.420 \\
.199\end{array}$ & & \\
\hline
\end{tabular}


at the .01 level and that between item types at the .05 level, $F(1,42)=9.03$ and 5.14 , respectively. It is to be noted that the scores of the recognition control subjects were intermediate between those of the two response-generation groups but closer to the HA than to the MA values.

The pattern of recall scores suggests that the interpolated tasks were conducive to retroactive inhibition, but that reexposure to individual target words tended to offset the interference. Hence, untested items were recalled less well than tested ones. The inferiority of the MA to the HA treatment implies that the detrimental effects on recall became more pronounced as the degree of associative connection between target words and distractors decreased. The fact that the discrepancy between stringent and lenient scores was greater for tested than for untested items suggests that the juxtaposition of extralist cues and TBR words served to impair specific associations established during the input trial.

The mean scores of the recall control group were .420 (stringent) and .460 (lenient). With one exception (the lenient scores under Condition HA), all the corresponding values shown in Table 8 are lower, although in some cases only slightly so. If the difference in retention intervals is disregarded for the moment, it becomes possible to infer that the interpolated tasks were more likely to depress than to enhance recall. In any event, it is apparent that the prior testing procedures had systematic effects on subsequent recall, effects which were item-specific and dependent on the characteristics of the extralist words encountered by the subject. Direct comparisons between recognition and recall based on successive tests are clearly hazardous.

Extralist intrusions in cued recall. An examination of the extralist intrusions on the final test of cued recall adds to the evidence that the interpolated test activities were a source of interference. Two types of intrusions were distinguished: (a) importations, i.e., words not encountered by the subject during the experimental session; and (b) prior test items. The latter included the extralist cues and distractors from the preceding test of recognition. (Distractors were, of course, presented to the recognition control group and produced as free associates by the responsegeneration groups.) The error frequencies were converted into percentages of total responses. The percentages of importations were comparable under all treatments: recall control, 10.4; recognition control, 11.4; Condition HA, 13.2; Condition MA, 11.5. The percentages of intrusions from the prior test for the last three groups were, in the order named, 12.0, 8.9, and 19.2. Clearly, there were frequent failures of differentiation between the TBR words and items encountered during the interpolated test. The high percentage of test-item intrusions under
Condition MA should be noted. Subjects may have tended to avoid giving two familiar responses that were strongly associated. Such a strategy would have been more difficult to implement under the MA procedure than under the other two treatments.

\section{Discussion}

The superiority of recall over recognition observed in previous studies using the generation-recognition procedure was not found in this experiment. It can be safely assumed that the subjects paid due attention to the weak cues presented on the input trial: more than $90 \%$ of the correct responses reproduced by the recall control subjects were given to the appropriate cues. It appears, therefore, that the encoding specificity effect indexed by the superiority of recall over recognition is not a robust one. This conclusion is supported, not only by the results obtained under the responsegeneration conditions, but also by the comparison of the two control groups.

The control data by themselves provide a straightforward test of the specificity principle. The use of the generation-recognition procedure entails inevitable complexities of interpretation. A more stringent criterion was adopted in the recognition phase by the response-generation than by the control subjects; the nature of the interpolated activity had systematic effects on subsequent cued recall. Contrary to expectations, however, the levels of recognition were comparable under Conditions HA and MA. Thus, the degree of semantic overlap between target words and secondary associates does not appear to be a critical factor, at least when the number of associates is restricted to two.

In view of the many differences in procedure and method of measurement, no firm conclusions can be drawn about the exact reasons for the divergence of the present findings from the earlier ones. The omission of set-inducing lists and the reduction of intrasession transfer effects are probable contributing factors. ${ }^{1}$ Since general laws of retrieval are at issue, the identification of a special set of manipulations that can produce a strong specificity effect is not of great interest. Thus, the intent of the present experiment was to assess the degree of encoding specificity in recognition under conditions that were designed to reduce, if not to eliminate, the influence of potentially important biases.

It is important not to overlook the fact that the proportion of items not recognized but recalled $(\overline{\mathrm{RgR}})$ was not entirely negligible, although it was relatively low. Such an outcome is observed very rarely under standard conditions of testing. Thus, it is only fair to say that there is some evidence for encoding specificity in the recognition data. The small magnitude of these effects indicates. however, that drastic cue-dependent changes in the semantic interpretation of TBR words 
were the exception rather than the rule.

\section{CONCLUSIONS}

The results of both experiments are at variance with earlier findings that were interpreted as critical evidence for a strong principle of encoding specificity. In Experiment I, strong extralist cues facilitated recall after presentation of the TBR words in the presence of weak cues. In Experiment II, recall to the original weak input cues failed to surpass recognition in the context of new strong cues. In each case, the procedures differed from those used earlier because it was deemed desirable to lessen the emphasis on pairwise contingencies during acquisition and to reduce or eliminate intraexperimental transfer effects. Such procedural variations should be of little consequence if strict cue dependence were a fundamental characteristic of the retrieval process. The apparent fragility of the phenomena at issue calls for continued caution in the invocation of a strong principle of encoding specificity.

We are by no means led to the assertion that retrieval cannot be affected by changes in the interpretation of TBR words attendant upon the introduction of new cues. The conclusion is, rather, that it will be well to formulate the issue of encoding specificity in less radical, all-or-none terms. It would be surprising, indeed, if the encoding of words were entirely independent of the cognitive environment in which they were originally encountered, and if the initial encoding did not influence subsequent retrieval. What is in doubt is the context-dependent pluralism of virtually independent encodings which is postulated by the principle of specificity in its strong form. As was suggested earlier, homographs do not provide us with a useful model for thinking about the variability of the interpretation of words. In most cases, changes in encoding are more likely to represent corrections of a relatively stable schema, variations on a theme rather than new themes. If that view is correct, it is at least as important to focus on encoding constancy as on encoding specificity in trying to understand the principles governing the effectiveness of retrieval cues.

\section{REFERENCES}

Anderson, J. R., \& Bower, G. Recognition and retrieval processes in free recall. Psychological Review, 1972, 79, 97-123.

BAHRICK, H. P. A two-phase model for prompted recall. Psychological Review, 1970, 77, 215-222.

BERnBACH, H. A. Stimulus learning and recognition in pairedassociate learning. Journal of Experimental Psychology, 1967, 75, 513-519.
Kintsch, W. Models for free recall and recognition. In D. A. Norman (Ed.), Models of human memory. New York: Academic Press, 1970.

Martin, E. Relation between stimulus recognition and pairedassociate learning. Journal of Experimental Psychology, 1967, 74, 500-505.

Murphy, M. D., \& Wallace, W. P. Encoding specificity: Semantic change between storage and retrieval cues. Journal of Experimental Psychology, 1974, 103, 768-774.

Nelson, D. L., Wheeler, J. W., JR., Borden, R. C., \& Brooks, D. H. Levels of processing and cuing: Sensory versus meaning features. Journal of Experimental Psychology, 1974, 103, 971-977.

Reder, L. M., Anderson, J. R., \& Bjork, R. A. A semantic interpretation of encoding specificity. Journal of Experimental Psychology, 1974, 102, 648-656.

SANTA, J. L., \& Lamwers, L. L. Encoding specificity: Fact or artifact. Joumal of Verbal Learning and Verbal Behavior, 1974, 13, 412-423.

Thomson, D. M., \& Tulving, E. Associative encoding and retrieval: Weak and strong cues. Journal of Experimental Psychology, 1970, 86, 255-262.

Tulving, E. Episodic and semantic memory. In E. Tulving and W. Donaldson (Eds.), Organization of memory. New York: Academic Press, 1972.

TULVING, E. Recall and recognition of semantically encoded words. Journal of Experimental Psychology, 1974, 102, 778-787.

Tulving, E., \& Thomson, D. M. Encoding specificity and retrieval processes in episodic memory. Psychological Review, 1973, 80, 352-373.

TwedT, H. M., \& UNDERwood, B. J. Mixed vs. unmixed lists in transfer studies. Journal of Experimental Psychology, 1959, 48, $111 \cdot 116$.

UNDERWOOD, B. J. The role of the association in recognition memory. Journal of Experimental Psychology, 1974, 102, 917-939.

Watkins, M. J., \& TulviNG, E. Episodic memory: When recognition fails. Journal of Experimental Psychology, 1975, 104, 5-29.

WOLFORD, G. Function of distinct associations for pairedassociate performance. Psychological Review, 1971, 78, 303-313. Woodworth, R. S. Experimental psychology. New York: Holt, 1938.

\section{NOTE}

1. After this paper was completed, I had an opportunity to read the article by Watkins and Tulving (1975) describing a series of experiments in which variants of the original generation-recognition procedure were employed. Substantial failure of recognition for recallable words was observed under a variety of treatments, although the effect was greatly reduced in the one experiment in which the free-association task was omitted. Several salient features of the earlier methodology were retained, particularly the administration of successive tests to the same subjects, including recall of the input cues for recognized targets prior to the final test of cued recall. In the absence of independent control groups, the differences between recognition and cued recall remain difficult to interpret. The administration of set-inducing lists was not found to be an important factor. In view of the apparent effectiveness of this manipulation in earlier investigations of extralist cuing in recall (Murphy \& Wallace, 1974; Thomson \& Tulving, 1970), this issue warrants further examination.

(Received for publication February 7, 1975; revision received March 24, 1975.) 